Sharif University of Technology
Scientia Iranica
SCIENTIA

\title{
An integrated approach of quality for polymer composite manufacturing validated and optimized through Taguchi method
}

\author{
M. Asima,*, M. Zubair Khan ${ }^{\mathrm{b}}$, L. Alam Khan ${ }^{\mathrm{c}}$ and M. Umer ${ }^{\mathrm{a}}$ \\ a. Department of Engineering, Management Center of Advanced Studies in Engineering G-5/1, Islamabad, Pakistan. \\ b. Department of Mechanical Engineering, Institute of Space Technology, Islamabad, Pakistan. \\ c. Center of Excellence on Science and Applied Technologies (CESAT), Islamabad, Pakistan.
}

Received 22 September 2015; received in revised form 8 March 2016; accepted 8 November 2016

\section{KEYWORDS \\ Quality; \\ Flexure strength; \\ Flexure stress; \\ Polymer; \\ Composite; \\ Taguchi method.}

\begin{abstract}
Quality problems in the polymer composite products are mainly attributed to design flaws, material inconsistencies, defects in manufacturing process, unqualified manpower, use of primitive technology, and defective machines. The purpose of this research is to develop a generic framework of quality for polymer composite manufacturing, which is validated and optimized through determining flexure properties by Taguchi method. To test the proposed framework, 27 polymer composite laminates were produced according to Taguchi $L_{27}$ orthogonal array by varying thirteen key process parameters including laminates' thickness, weight, fiber pattern, matrix, core type, resin and hardener mixing time, viscosity, layup pattern, tooling, cure, temperature, labour and process techniques. Flexure strength was defined as quality characteristic, and accordingly, effects of the selected parameters on flexural properties were studied through three-point bending test. Results of the study reveal that fiber pattern, cure, tooling type, and layup pattern are the most significant variables influencing flexure stress, whereas fiber pattern, matrix, resin hardening mixing time, and process techniques have significant effect on flexure strain. The optimized levels of each control parameter for flexure stress and strain were obtained, and results were validated through predictive analysis. Findings of this study and the proposed framework are useful for polymer composite application in aviation, mechanical, sports, automobile, and civil industries.
\end{abstract}

(C) 2017 Sharif University of Technology. All rights reserved.

\section{Introduction}

Material properties, such as mechanical, chemical, and physical ones, are embedded during the polymer composite manufacturing process [1]. Small variation in raw material, processing, tooling, laying or autoclave

\footnotetext{
Corresponding author. Tel.: +9251843 2273;

Fax: +92 518314660

E-mail addresses: a007pk@yahoo.com (M. Asim);

Zubair_kj@yahoo.com (M. Zubair_Khan);

laraibkh@gmail.com (L. Alam Khan); mumer@case.edu.pk (M. Umer);
}

loading could result in a large amount of variation in cured composite parts [2]. For acceptable products, all key manufacturing control parameters, such as environment control, raw material control, production tolerances, dimensional tolerance control, thermal control, etc., have to conform to pre-established production criteria. Certain tests are needed to control mechanical, chemical, and physical properties along with development and documentation of process conditions [3]. It is very difficult to detect material defects through quality control tests such as incoming material inspections and acceptance procedures. John and Yeow [4] put empha- 
sis on the process and end of product properties. They classified 66 prepreg vital characteristics and process parameters that have major effect on properties of structure. Out of those, 26 characteristics significantly affected the structural performance. According to Galappaththil et al., manufacturing dichotomies and inconsistencies of resin infusion process could be reduced by controlling key control process parameters [5]. Potter et al. reviewed the causes of inconsistencies in aviation composite parts and recommended robust design in manufacturing process [6]. They identified 130 defect types, 60 sources of variability in material, molding and post-molding process in autoclave and resin transfer molding techniques. Quality problem in the composite products is mainly attributed to design flaws, material inconsistencies, defects in manufacturing process, untrained/unqualified manpower, and defective machines. Common problems faced by the composite industries include imperfections in parts, excessive labour involvement, complexity in machining operations, intricacies in manufacturing, assembly and bonding, which resulted in quality, ergonomics, and serviceability problems. The problems and difficulties encountered during manufacturing parts are ultimately responsible for higher rejection rate and increased production cost $[7,8]$.

\section{Description}

Although researchers have done an appreciable amount of work on quality control, quality assurance, and various sources of variability in composite manufacturing processes, the existing literature lacks the integrated quality framework, which could be applicable to various polymer composite production processes and could facilitate manufacturers to provide key variables specific to different stages of manufacturing. This research is aimed to integrate the variables involved in design, material, key process control parameters, and testing of polymer composite manufacturing into one generic framework, and accordingly, their effects on the product quality are studied. Then, the developed framework is tested and validated through determination of flexure properties by using design of experiment technique. The paper is organized in the following chronological order: Section 2.1 describes the problem formulation; Section 2.2 represents the proposed quality framework; Section 3 elucidates the research methodology and data collection technique; Section 4 represents results and discussion; Section 5 focuses on conclusion and area of future research.

\subsection{Problem formulation}

Problem for this research has been formulated in the following way: a. Integrated quality framework is developed for polymer composite manufacturing;

b. Key control parameters affecting product quality are selected;

c. Polymer composite laminates are manufactured according to Taguchi $L_{27}$ orthogonal array by varying the levels of selected control parameters;

d. Three-point bending test of specimens as per ASTM standard D 790;

e. Flexural strength and flexure strain are measured and defined as quality characteristics of composite laminates;

f. Statistical analysis is performed with the help of Signal to Noise $(S / N)$ ratio to determine the significant effect of each variable on flexure properties;

g. Optimized level of each parameter is determined;

h. Validation of results is accomplished through predictive analysis.

\subsection{The proposed framework}

Product quality of composite products is defined in terms of mechanical, chemical, and physical properties such as ultimate strength, flexure strength, tensile strength, compressive strength, conformance to dimensions, voids, delamination, etc. [9]. The types of manufacturing equipment, specialized tooling, and inspection techniques have distinct effect on the design of composites. As the material is prepared during the part fabrication, concurrent engineering design approach, meticulous material, and production processes must be selected to get the required properties. Key design parameters are to be defined at the concept definition phase of the design cycle including calculation of maximum allowable loads, weight estimation, thickness, stress analysis, damage tolerance, etc. [10-12]. There are numerous process control variables involved in the manufacturing process that can be classified into three subgroups including material, in-process control parameters, and inspection techniques [1-6,9]. Quality Control (QC) and Quality Assurance (QA) parameters for in-process control variables are dependent on the manufacturing method used in developing a product. Each production method has specific tooling, laying procedure, and unique machines. Accordingly, the skill of labour, environmental conditions, storage, and handling procedures is varied. The manufactured composite parts must be checked for any damage/defects with the help of destructive and non-destructive tests. QC system ensures materials quality, control of process parameters, and procedure for testing to compare the end product properties with the desired design requirements $[1,3,9]$. QA of composites is ensured through conforming testing to guarantee the sustained reliability of a composite material, control parameters 

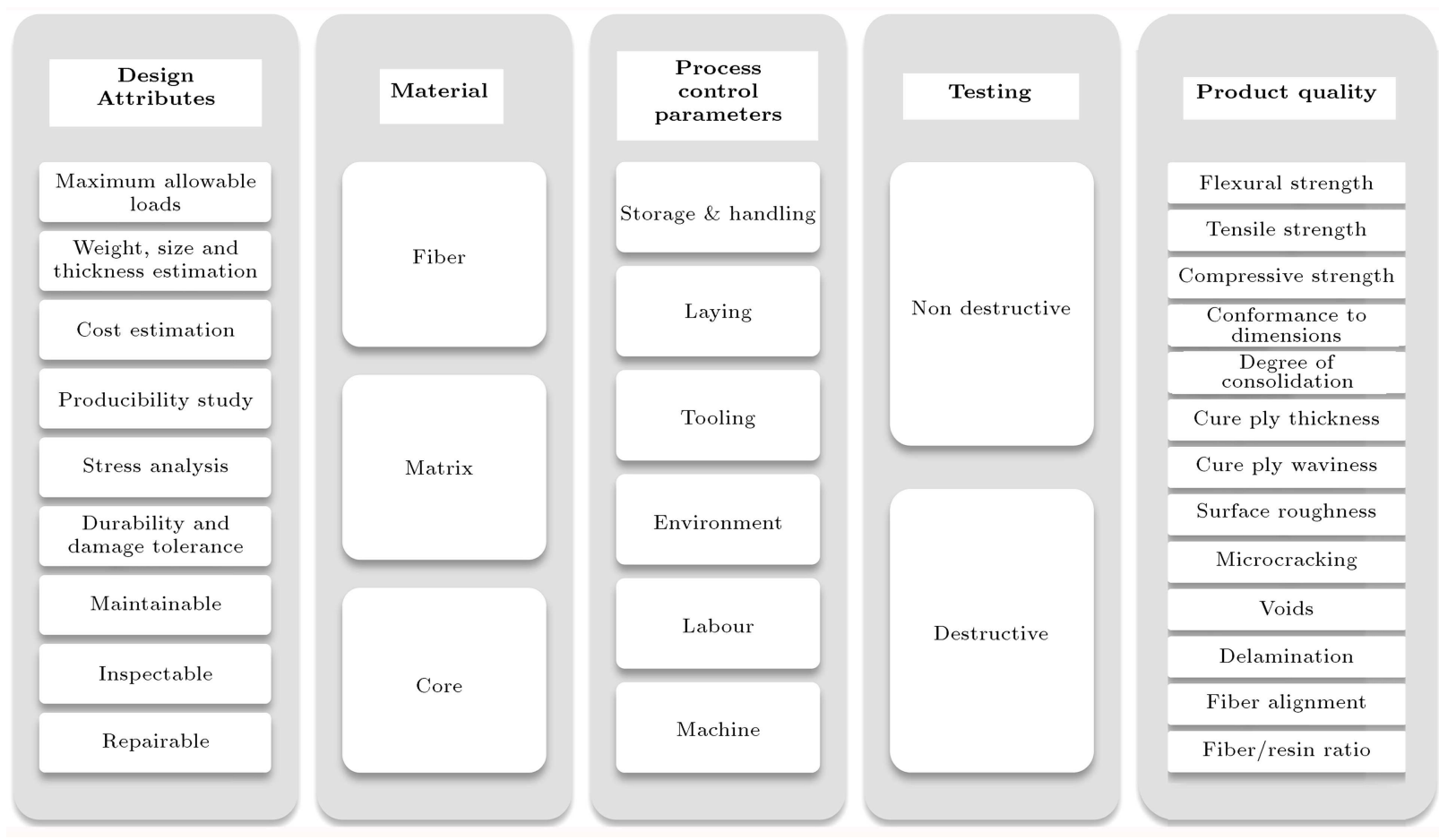

Figure 1. The proposed quality framework.

of process, and quality of finished parts $[9,10]$. Based on the literature, all key design parameters, manufacturing key variables, and product quality attributes are gathered and integrated into one framework as shown in Figure 1.

\subsection{Selection of key variables}

Desired product quality is required to be embedded right from the design stage. As an initial step, product and process specifications are defined and design attributes are estimated. Selection of appropriate materials, such as fiber type, matrix, and core, are finalized based on required technical characteristics. Subsequently, peculiar settings of process control parameters are ensured, and the product is produced as per laid down criteria. The product quality is then measured through a series of non-destructive and destructive testing procedures to validate the desired quality characteristics. For the purpose of this study, thirteen key variables from various stages of manufacturing, including design, material, and process control parameters, were selected to test the proposed framework. Weight and thickness were selected from design stage. Fiber type, matrix, and core type were chosen from the material. Resin hardening mixing time, viscosity, layup pattern, tooling, cure type, temperature, labour type and process technique were selected from the process control parameters. Accordingly, polymer composite sandwich laminates were produced by varying the values of these variables. Samples were tested through destructive testing technique (three-point bending), and then flexural strength was calculated to measure the product quality.

\section{Methodology}

Taguchi method was applied to test the proposed framework. The approach follows a set pattern involving multi-stage sequential process to obtain the best results. Taguchi process is made up of four phases including the planning phase, experimental phase, data analysis phase, and validation phase. The planning phase is the most critical phase because the problem/objective, identification of control factors, and appropriate orthogonal array are selected and defined. In subsequent phases, data are collected from all the experiments and the effects of various process parameters on quality characteristics followed by optimum level determination and validation are analyzed [13-15]. Step-wise application of Taguchi method is shown in Figure 2.

\subsection{Application of Taguchi method}

Taguchi method is applied in the following steps:

- Step 1: Problem Definition. The first step in the Taguchi method is to determine the quality characteristic which is to be optimized. The quality characteristic is a parameter whose variation has a critical effect on product quality. It is an output or response variable to be observed. The objective of the proposed quality framework is to maximize the product quality of polymer composite products. 


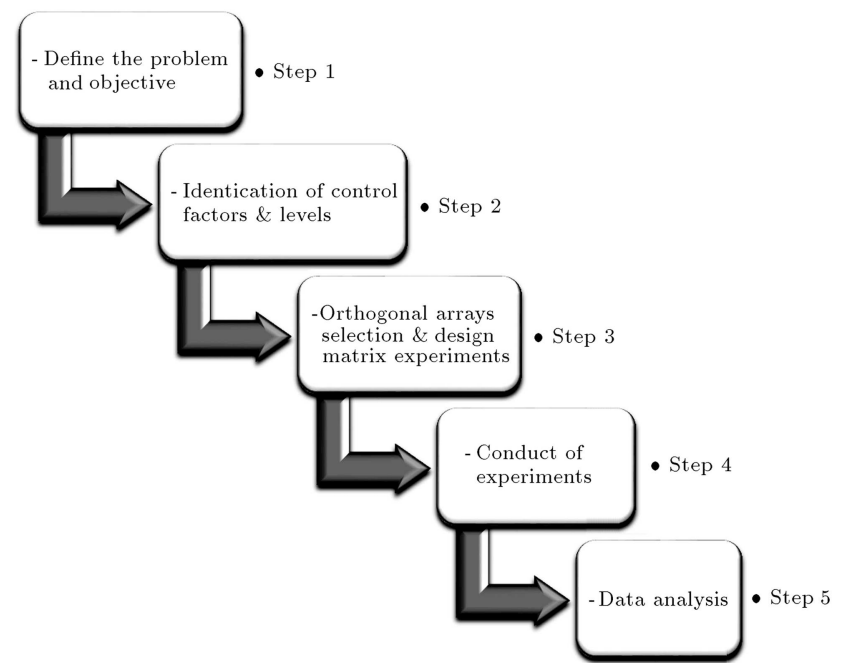

Figure 2. Flowchart representing step-wise Taguchi method.

The proposed quality framework highlights thirteen attributes of product quality (Figure 1). In the present study, flexure strength is selected to determine the product quality of polymer composites, and accordingly, the effects of process variables on flexure strength are studied. Therefore, flexure stress and flexure strain are defined as quality characteristics;

- Step 2: Selection of control factors and corresponding levels. The next stage is to categorize the control factors that influence the system performance and quality. Thirteen key parameters were selected including weight $(A)$, thickness $(B)$, fiber type $(C)$, matrix $(D)$, core type $(E)$, resin hardening mixing time $(F)$, viscosity $(G)$, layup pattern $(H)$, tooling $(J)$, cure $(K)$, temperature $(L)$, labour $(M)$, and process technique $(N)$. The values of each control parameter were varied at three levels. Control parameters along with each of three values are presented in Table 1.

- Step 3: Selection of orthogonal array and experimental matrix. Taguchi standardized orthogonal arrays were developed for various variables with corresponding levels [16]. $L_{27}$ orthogonal array was selected from various sets of orthogonal arrays due to involvement of 13 parameters at each of 3 levels. The same is also verified through degrees of freedom approach with the help of Eq. (1) [17]. $L_{27}$ array consists of 27 rows (experimental runs) and 13 columns (controlling parameters). Data of each parameter with corresponding levels are shown in Table 2 .

$$
N_{\text {Taguchi }}=\sum_{i=1}^{N V}(L i-1),
$$

where:

$N \quad$ Number of experiments;

$N V \quad$ Number of independent variables;

$L \quad$ Number of levels of each variable.

- Step 4: Conduct of experiments. 27 composite sandwich laminates, each measuring $220 \times 200 \mathrm{~mm}$, were manufactured by varying levels of control parameters, as mentioned in Table 2. Sample photographs of laminates are shown in Figure 3. Three test specimens were derived from each laminate $(27 \times 3=81)$ with the help of 4 -axis universal milling machine model XQ6232WA according to dimensions, defined by ASTM standard D 790 [18].

Table 1. Experimental parameters and input levels.

\begin{tabular}{|c|c|c|c|c|}
\hline Symbol & Description & Level 1 & Level 2 & Level 3 \\
\hline$A$ & Weight & $50 \mathrm{~g}$ & $85 \mathrm{~g}$ & $80 \mathrm{~g}$ \\
\hline$B$ & Thickness & $5 \mathrm{~mm}$ & $11 \mathrm{~mm}$ & $10 \mathrm{~mm}$ \\
\hline$C$ & Fiber type & Unidirectional (UD) & Woven $3 \mathrm{~K}$ filament (W3K) & Woven $1 \mathrm{~K}$ Filament (W1K) \\
\hline$D$ & Matrix & Epoxy (EP) & Poly Epoxy (PE) & Polyester (PY) \\
\hline$E$ & Core type & Foam (FM) & Honey Comb $4 \mathrm{~mm}$ ( $\mathrm{HC} \mathrm{4)}$ & Honey Comb $8 \mathrm{~mm}$ (HC 8) \\
\hline$F$ & $\begin{array}{l}\text { Resin harden } \\
\text { mixing time }\end{array}$ & 0 minutes & 6 minutes & 12 minutes \\
\hline$G$ & Viscosity & 900 mPa.s & $1150 \mathrm{mPa} . \mathrm{s}$ & $1650 \mathrm{mPa} . \mathrm{s}$ \\
\hline$H$ & Layup pattern & $0^{\circ}, 90^{\circ}$ & $0^{\circ}, 45^{\circ}, 90^{\circ}$ & $30^{\circ}, 60^{\circ}, 90^{\circ}$ \\
\hline$J$ & Tooling & Carbon (CR) & Aluminum (AL) & Fiber Glass (FG) \\
\hline$K$ & Cure & Without Post Cure (WPC) & Post cure at $50^{\circ} \mathrm{C}(\mathrm{PC} 50)$ & Post cure at $70^{\circ} \mathrm{C}(\mathrm{PC} 70)$ \\
\hline$L$ & Temperature & $15^{\circ} \mathrm{C}$ & $22^{\circ} \mathrm{C}$ & $30^{\circ} \mathrm{C}$ \\
\hline$M$ & Labour & $\mathrm{X}$ & $\mathrm{Y}$ & $\mathrm{Z}$ \\
\hline$N$ & Process technique & Wet Lay up (WL) & Vacuum Bagging (VB) & Vacuum Infusion (VI) \\
\hline
\end{tabular}


Table 2. $L_{27}$ Orthogonal array with the corresponding values of each parameter.

\begin{tabular}{|c|c|c|c|c|c|c|c|c|c|c|c|c|c|}
\hline Run & $\boldsymbol{A}$ & $B$ & $C$ & $D$ & $E$ & $F$ & $G$ & $\boldsymbol{H}$ & $\boldsymbol{J}$ & $K$ & $L$ & $M$ & $N$ \\
\hline 1 & 50 & 5 & UD & EP & $\mathrm{HC} 4$ & 0 & 900 & 0,90 & $\mathrm{CR}$ & WPC & 15 & $X$ & WL \\
\hline 2 & 50 & 5 & UD & EP & FM & 6 & 1150 & $0,45,90$ & $\mathrm{AL}$ & PC 50 & 22 & $Y$ & VB \\
\hline 3 & 50 & 5 & UD & $\mathrm{EP}$ & $\mathrm{HC} 8$ & 12 & 1650 & $30,60,90$ & FG & PC 70 & 30 & $Z$ & VI \\
\hline 4 & 50 & 11 & W3K & $\mathrm{PE}$ & $\mathrm{HC} 4$ & 0 & 900 & $0,45,90$ & $\mathrm{AL}$ & PC 50 & 22 & $Y$ & VI \\
\hline 5 & 50 & 11 & W3K & $\mathrm{PE}$ & FM & 6 & 1150 & $30,60,90$ & FG & PC 70 & 30 & $Z$ & WL \\
\hline 6 & 50 & 11 & W3K & $\mathrm{PE}$ & $\mathrm{HC} 8$ & 12 & 1650 & 0,90 & $\mathrm{CR}$ & WPC & 15 & $X$ & VB \\
\hline 7 & 50 & 10 & W1K & PY & $\mathrm{HC} 4$ & 0 & 900 & $30,60,90$ & FG & PC 70 & 30 & $Z$ & VB \\
\hline 8 & 50 & 10 & W1K & PY & FM & 6 & 1150 & 0,90 & $\mathrm{CR}$ & WPC & 15 & $X$ & VI \\
\hline 9 & 50 & 10 & W1K & PY & $\mathrm{HC} 8$ & 12 & 1650 & $0,45,90$ & $\mathrm{AL}$ & PC 50 & 22 & $Y$ & WL \\
\hline 10 & 85 & 5 & W3K & PY & $\mathrm{HC} 4$ & 6 & 1150 & $30,60,90$ & CR & PC 70 & 22 & $Z$ & WL \\
\hline 11 & 85 & 5 & W3K & PY & FM & 12 & 1650 & 0,90 & $\mathrm{AL}$ & WPC & 30 & $X$ & VB \\
\hline 12 & 85 & 5 & W3K & PY & HC 8 & 0 & 900 & $0,45,90$ & FG & PC 50 & 15 & $Y$ & VI \\
\hline 13 & 85 & 11 & W1K & $\mathrm{EP}$ & HC 4 & 6 & 1150 & $30,60,90$ & $\mathrm{AL}$ & WPC & 30 & $X$ & VI \\
\hline 14 & 85 & 11 & W1K & EP & $\mathrm{FM}$ & 12 & 1650 & 0,90 & $\mathrm{FG}$ & PC 50 & 15 & $Y$ & WL \\
\hline 15 & 85 & 11 & W1K & $\mathrm{EP}$ & $\mathrm{HC} 8$ & 0 & 900 & $0,45,90$ & $\mathrm{CR}$ & PC 70 & 22 & $Z$ & VB \\
\hline 16 & 85 & 10 & UD & $\mathrm{PE}$ & $\mathrm{HC} 4$ & 6 & 1150 & $30,60,90$ & FG & PC 50 & 22 & $X$ & VB \\
\hline 17 & 85 & 10 & UD & $\mathrm{PE}$ & FM & 12 & 1650 & 0,90 & $\mathrm{CR}$ & PC 70 & 22 & $Z$ & VI \\
\hline 18 & 85 & 10 & UD & $\mathrm{PE}$ & $\mathrm{HC} 8$ & 0 & 900 & $0,45,90$ & $\mathrm{AL}$ & WPC & 30 & $X$ & WL \\
\hline 19 & 80 & 5 & W1K & $\mathrm{PE}$ & $\mathrm{HC} 4$ & 12 & 1650 & $0,45,90$ & $\mathrm{CR}$ & PC 50 & 30 & $Y$ & WL \\
\hline 20 & 80 & 5 & W1K & $\mathrm{PE}$ & FM & 0 & 900 & $30,60,90$ & $\mathrm{AL}$ & PC 70 & 15 & $Z$ & VB \\
\hline 21 & 80 & 5 & W1K & $\mathrm{PE}$ & HC 8 & 6 & 1150 & 0,90 & FG & WPC & 22 & $X$ & VI \\
\hline 22 & 80 & 11 & UD & PY & $\mathrm{HC} 4$ & 12 & 1650 & $0,45,90$ & $\mathrm{AL}$ & PC 70 & 15 & $Z$ & VI \\
\hline 23 & 80 & 11 & UD & PY & FM & 0 & 900 & $30,60,90$ & FG & WPC & 22 & $X$ & WL \\
\hline 24 & 80 & 11 & UD & PY & $\mathrm{HC} 8$ & 6 & 1150 & 0,90 & $\mathrm{CR}$ & PC 50 & 30 & $Y$ & VB \\
\hline 25 & 80 & 10 & W3K & EP & $\mathrm{HC} 4$ & 12 & 1650 & $0,45,90$ & FG & WPC & 22 & $X$ & VB \\
\hline 26 & 80 & 10 & W3K & $\mathrm{EP}$ & FM & 0 & 900 & $30,60,90$ & $\mathrm{CR}$ & PC 50 & 30 & $Y$ & VI \\
\hline 27 & 80 & 10 & W3K & EP & $\mathrm{HC} 8$ & 6 & 1150 & 0,90 & $\mathrm{AL}$ & PC 70 & 15 & $Z$ & WL \\
\hline
\end{tabular}

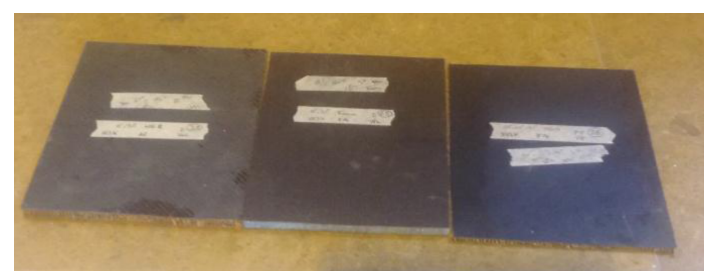

Figure 3. Sample of composite sandwich laminates.

The pictures of milling machine/cutting operation and test specimens are shown in Figures 4 and 5 , respectively. Each test specimen was subjected to three-point bend loading through Schimadzu ${ }^{\mathrm{TM}}$ UTM $(20 \mathrm{kN})$ autograph AG-X plus, as shown in Figure 6 .

Load was applied to each specimen at specified crosshead rate; accordingly, load deflection data, including maximum flexure stress, corresponding strain, and load deflection curve, were recorded simultaneously with the help of integrated Trapezi-
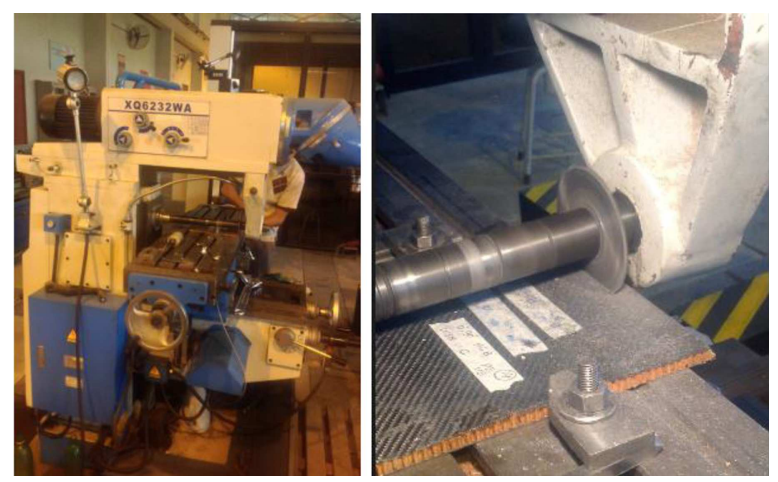

Figure 4. Universal milling machine and cutting operation.

umx software connected with universal testing machine. Failure pattern of different specimens is shown in Figure 7.

- Step 5: Data analysis. Values of maximum flexural stress and corresponding strain for all 81 

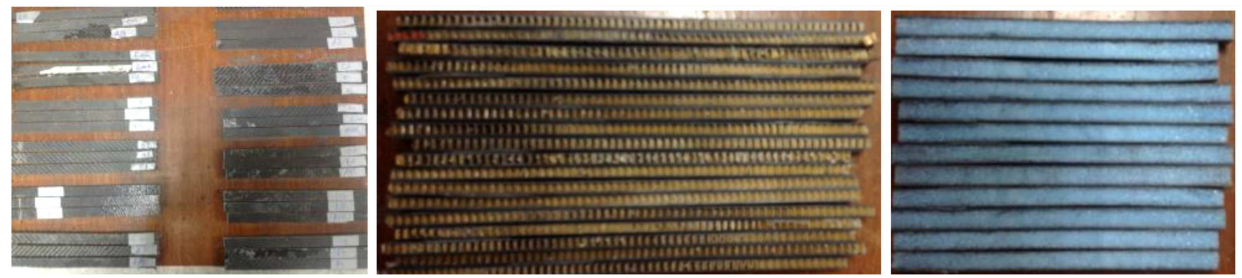

Figure 5. Test specimens.

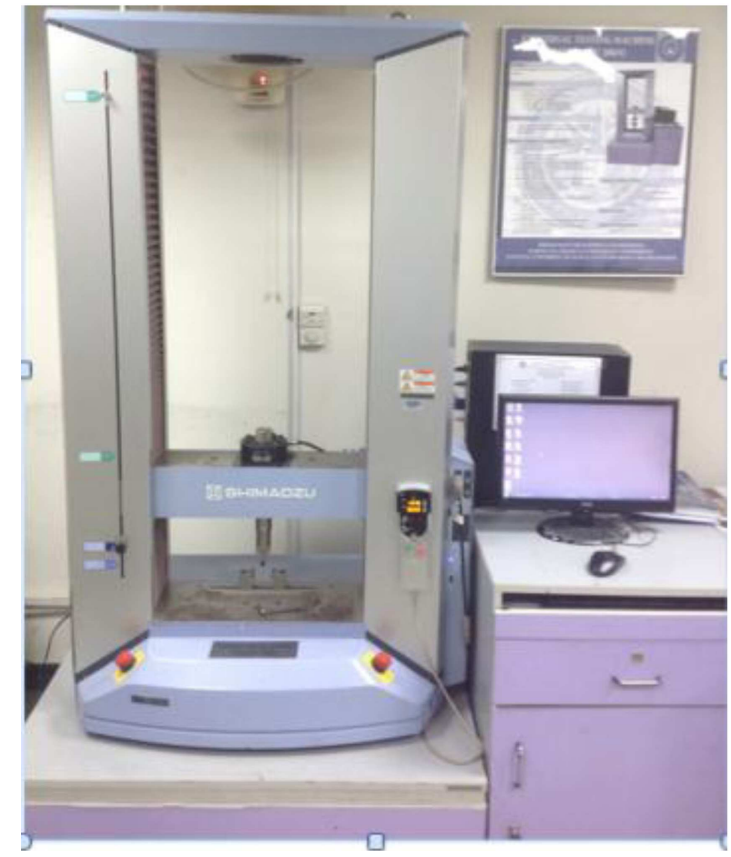

Figure 6. Universal testing machine with three-point bend set up.

samples were calculated as per Eqs. (2) and (3), respectively [18]. Minitab software version 18 was used for statistical analysis:

$$
\begin{aligned}
& \sigma_{f}=3 P L / 2 b d^{2}, \\
& \varepsilon_{f}=6 D d / L^{2},
\end{aligned}
$$

where:

$\sigma_{f} \quad$ Flexure stress in the outer fibers at midpoint, $\mathrm{N} / \mathrm{mm}^{2}$

$P \quad$ Load at a given point on the load-deflection curve, $\mathrm{N}$

L Support span, mm

$b \quad$ Width of beam tested, mm

$d \quad$ Depth of beam tested, $\mathrm{mm}$

$\varepsilon_{f} \quad$ Flexure strain in the outer surface, $\mathrm{mm} / \mathrm{mm}$

$D \quad$ Maximum deflection of the center of the beam, mm

The results are analysed through Signal-to-Noise $(S / N)$ ratio extracted from electrical control theory. The $S / N$ ratio is measured by calculating mean and variation; therefore, it is the ratio of signal (mean) to the noise (standard deviation) [19]. Three $S / N$ ratios are commonly used in Taguchi method including situations in which the required characteristics are either bigger the best (strength), smaller the best (vibrations), or nominal the best (dimensions). In this study, bigger the best was selected for measuring flexure stress $S / N_{\sigma}$ ratio (Eq. (4)), whereas smaller the best was selected for measuring flexure strain $S / N_{\varepsilon}$ ratio (Eq. (5)) [19]. Data of flexure stress and corresponding strain against each experiment
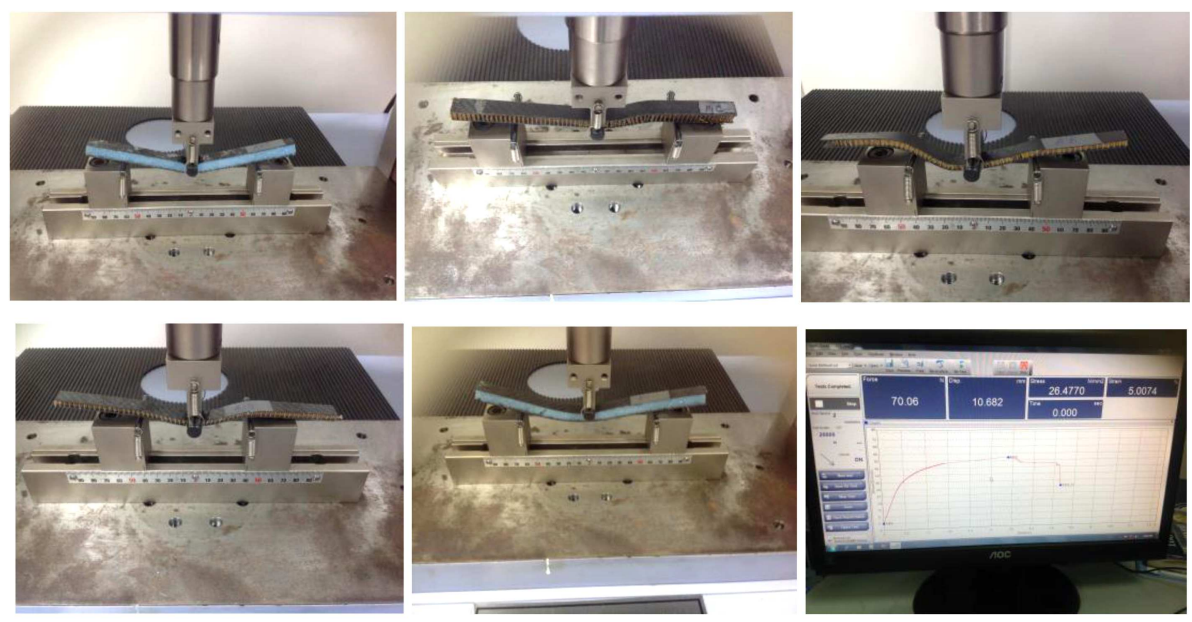

Figure 7. Failure patterns of different specimens and load deflection curve. 
Table 3. Values of flexure stress, flexure strain, and $S / N$ ratio.

\begin{tabular}{|c|c|c|c|c|c|c|c|c|c|c|}
\hline \multirow{2}{*}{ 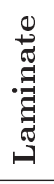 } & \multicolumn{5}{|c|}{$\begin{array}{c}\text { Flexure stress } \\
\left(\mathrm{N} / \mathrm{mm}^{2}\right)\end{array}$} & \multicolumn{4}{|c|}{$\begin{array}{c}\text { Flexure strain } \\
\% \\
\end{array}$} & \multirow[b]{2}{*}{$S / N_{\varepsilon}$} \\
\hline & $\begin{array}{c}\text { Sample } \\
1 \\
\end{array}$ & $\begin{array}{c}\text { Sample } \\
2 \\
\end{array}$ & $\begin{array}{c}\text { Sample } \\
3\end{array}$ & Mean & $S / N_{\sigma}$ & $\begin{array}{c}\text { Sample } \\
1\end{array}$ & $\begin{array}{c}\text { Sample } \\
2 \\
\end{array}$ & $\begin{array}{c}\text { Sample } \\
3 \\
\end{array}$ & Mean & \\
\hline 1 & 50.719 & 55.042 & 55.572 & 53.771176666 & 34.589 & 3.366 & 2.262 & 3.585 & 3.071 & 5.407 \\
\hline 2 & 38.138 & 35.226 & 40.126 & 37.83 & 31.519 & 1.604 & 1.343 & 1.563 & 1.503333333 & 9.212 \\
\hline 3 & 6.177 & 8.14 & 5.075 & 6.464 & 15.733 & 5.04 & 5.14 & 4.965 & 5.048333333 & 2.274 \\
\hline 4 & 16.662 & 15.979 & 25.225 & 19.28866667 & 25.185 & 1.382 & 2.137 & 1.986 & 1.835 & 2.800 \\
\hline 5 & 1.457 & 1.689 & 2.357 & 1.834333333 & 4.764 & 4.959 & 0.471 & 0.457 & 1.962333333 & 1.701 \\
\hline 6 & 15.387 & 15.388 & 19.605 & 16.79333333 & 24.338 & 1.335 & 1.335 & 1.225 & 1.298333333 & 1.682 \\
\hline 7 & 29.482 & 34.602 & 40.596 & 34.89333333 & 30.634 & 0.732 & 0.68 & 0.759 & 0.723666667 & 1.0382 \\
\hline 8 & 44.241 & 34.697 & 54.241 & 44.393 & 32.514 & 0.792 & 0.7 & 0.954 & 0.815333333 & 9.526 \\
\hline 9 & 58.044 & 60.265 & 50.983 & 56.43066667 & 34.962 & 1.164 & 1.343 & 1.123 & 1.21 & 1.309 \\
\hline 10 & 14.728 & 16.634 & 10.689 & 14.017 & 22.472 & 1.222 & 0.802 & 0.475 & 0.833 & 2.049 \\
\hline 11 & 6.029 & 6.03 & 1.457 & 4.505333333 & 7.560 & 1.023 & 1.125 & 4.959 & 2.369 & 1.139 \\
\hline 12 & 8.5786 & 1.587 & 7.401 & 5.855533333 & 8.447 & 1.587 & 0.351 & 1.189 & 1.042333333 & 0.222 \\
\hline 13 & 23.797 & 25.747 & 39.335 & 29.62633333 & 28.837 & 0.637 & 0.691 & 0.994 & 0.774 & 2.938 \\
\hline 14 & 41.581 & 38.905 & 43.657 & 41.381 & 32.306 & 0.972 & 0.836 & 0.815 & 0.874333333 & 10.991 \\
\hline 15 & 49.099 & 43.922 & 55.205 & 49.40866667 & 33.763 & 0.865 & 0.883 & 1.15 & 0.966 & 7.940 \\
\hline 16 & 82.347 & 94.134 & 102.832 & 93.10433333 & 39.270 & 1.324 & 1.41 & 1.47 & 1.401333333 & 2.233 \\
\hline 17 & 39.742 & 56.485 & 20.243 & 38.82333333 & 29.473 & 5.00 & 3.467 & 0.8191 & 3.095366667 & 5.920 \\
\hline 18 & 32.605 & 23.255 & 23.255 & 26.37166667 & 28.107 & 1.784 & 2.783 & 2.783 & 2.45 & 4.748 \\
\hline 19 & 36.211 & 52.807 & 41.531 & 43.51633333 & 32.464 & 1.316 & 1.205 & 1.354 & 1.291666667 & 4.602 \\
\hline 20 & 16.655 & 7.742 & 5.886 & 10.09433333 & 17.855 & 1.098 & 2.137 & 2.44 & 1.891666667 & 0.848 \\
\hline 21 & 60.186 & 54.838 & 68.055 & 61.02633333 & 35.609 & 1.5 & 2.278 & 1.23 & 1.669333333 & 2.737 \\
\hline 22 & 11.402 & 10.537 & 10.537 & 10.82533333 & 20.671 & 1.186 & 1.904 & 1.904 & 1.664666667 & 4.436 \\
\hline 23 & 40.876 & 52.233 & 39.528 & 44.21233333 & 32.716 & 0.831 & 0.997 & 1.401 & 1.076333333 & 9.356 \\
\hline 24 & 68.263 & 75.123 & 68.866 & 70.75066667 & 36.970 & 0.844 & 0.743 & 0.577 & 0.721333333 & 0.850 \\
\hline 25 & 7.985 & 7.468 & 18.723 & 11.392 & 19.152 & 0.987 & 0.897 & 2.56 & 1.481333333 & 5.407 \\
\hline 26 & 17.584 & 18.608 & 25.345 & 20.51233333 & 25.918 & 2.684 & 2.941 & 3.165 & 2.93 & 9.212 \\
\hline 27 & 8.078 & 3.851 & 3.85 & 5.259 & 13.003 & 0.805 & 1.225 & 1.225 & 1.085 & 2.274 \\
\hline
\end{tabular}

are presented in Table 3.

$$
\begin{aligned}
& S / N_{\sigma}=-10 * \log \left\{\Sigma\left(1 / Y^{2}\right) / n\right\} \\
& \left.S / N_{\varepsilon}=-10 * \log \left\{\Sigma\left(Y^{2}\right) / n\right)\right\}
\end{aligned}
$$

where:

$$
\begin{array}{ll}
S & \text { Signal } \\
N & \text { Noise } \\
Y & \text { Mean of sum of square } \\
n & \text { Number of samples }
\end{array}
$$

After determination of $S / N$ ratio for each experiment, the $S / N$ ratio of each control parameter was calculated. $S / N_{\sigma}$ ratio of flexure stress computed for each control parameter is tabulated in Table 4 , whereas $S / N_{\varepsilon}$ ratio of flexure strain computed for each control parameter is shown in Table 5. Ranking of $S / N$ ratios was done according to the amount of variation produced by each control parameter in response variables (flexure stress and strain). Maximum variation of $S / N$ ratio at three levels in the given parameter means significant impact on response variable, and vice versa. Corresponding graphs highlighting variation of each control parameter are shown in Figures 8 (flexure stress) and 9 (flexure strain).

\section{Results and discussion}

It is inferred from Table 4 and Figure 8 that fiber pattern, cure, type of tooling, and layup pattern are 
Table 4. Response table for $S / N_{\sigma}$ ratio of flexure stress.

\begin{tabular}{|c|c|c|c|c|c|c|c|c|c|c|c|c|c|}
\hline 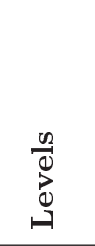 & $\begin{array}{l}\frac{\overrightarrow{1}}{80} \\
\frac{80}{0} \\
B\end{array}$ & 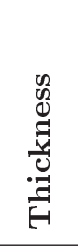 & 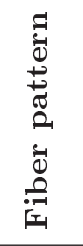 & 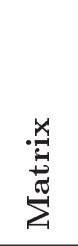 & $\begin{array}{l}0 \\
\dot{0} \\
ن\end{array}$ & 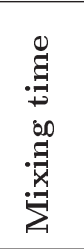 & 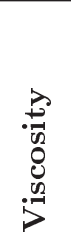 & 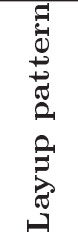 & 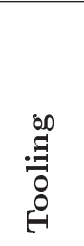 & 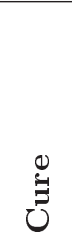 & 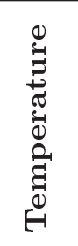 & 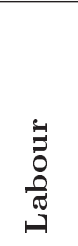 & $\begin{array}{l}n \\
0 \\
0 \\
0 \\
0 \\
0 \\
n\end{array}$ \\
\hline 1 & 25.6 & 25.6 & 30.2 & 26.2 & 27.5 & 28.0 & 28.7 & 30.3 & 27.0 & 27.7 & 26.6 & 25.5 & 26.8 \\
\hline 2 & 26.9 & 28.8 & 18.9 & 27.0 & 25.4 & 27.4 & 24.5 & 25.3 & 29.6 & 30.3 & 27.9 & 28.0 & 27.1 \\
\hline 3 & 27.9 & 26.1 & 31.3 & 27.2 & 27.5 & 25.0 & 27.2 & 24.8 & 23.8 & 22.3 & 25.8 & 26.9 & 26.4 \\
\hline Delta & 2.37 & 3.21 & 12.4 & 0.99 & 2.07 & 3.01 & 4.15 & 5.44 & 5.75 & 8.01 & 2.08 & 2.49 & 0.68 \\
\hline Rank & 9 & 6 & 1 & 12 & 11 & 7 & 5 & 4 & 3 & 2 & 10 & 8 & 13 \\
\hline
\end{tabular}

Table 5. Response table for $S / N_{\varepsilon}$ ratio of flexure strain.

\begin{tabular}{|c|c|c|c|c|c|c|c|c|c|c|c|c|c|}
\hline 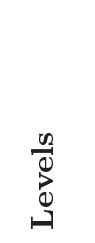 & 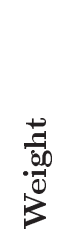 & 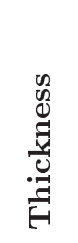 & 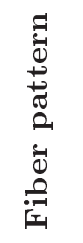 & 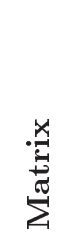 & $\begin{array}{c}0 \\
0 \\
0\end{array}$ & 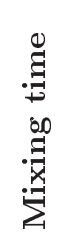 & 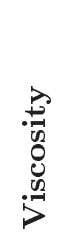 & 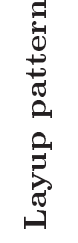 & 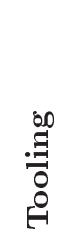 & $\underset{\Xi}{\Xi}$ & 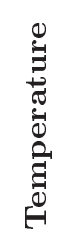 & 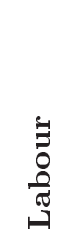 & $\begin{array}{l}n \\
0 \\
0 \\
0 \\
0 \\
0 \\
0\end{array}$ \\
\hline 1 & 4.62 & 5.58 & 5.79 & 4.30 & 2.62 & 4.18 & 3.86 & 3.22 & 2.77 & 3.99 & 3.38 & 4.29 & 5.74 \\
\hline 2 & 3.36 & 3.74 & 4.59 & 5.74 & 5.17 & 1.53 & 3.48 & 4.16 & 3.38 & 2.51 & 2.54 & 3.05 & 1.91 \\
\hline 3 & 3.13 & 1.79 & 0.74 & 1.07 & 3.32 & 5.40 & 3.77 & 3.73 & 4.97 & 4.62 & 5.19 & 3.77 & 3.46 \\
\hline Delta & 1.48 & 3.78 & 5.04 & 4.66 & 2.55 & 3.87 & 0.37 & 0.93 & 2.19 & 2.10 & 2.64 & 1.23 & 3.83 \\
\hline Rank & 10 & 5 & 1 & 2 & 7 & 3 & 13 & 12 & 8 & 9 & 6 & 11 & 4 \\
\hline
\end{tabular}

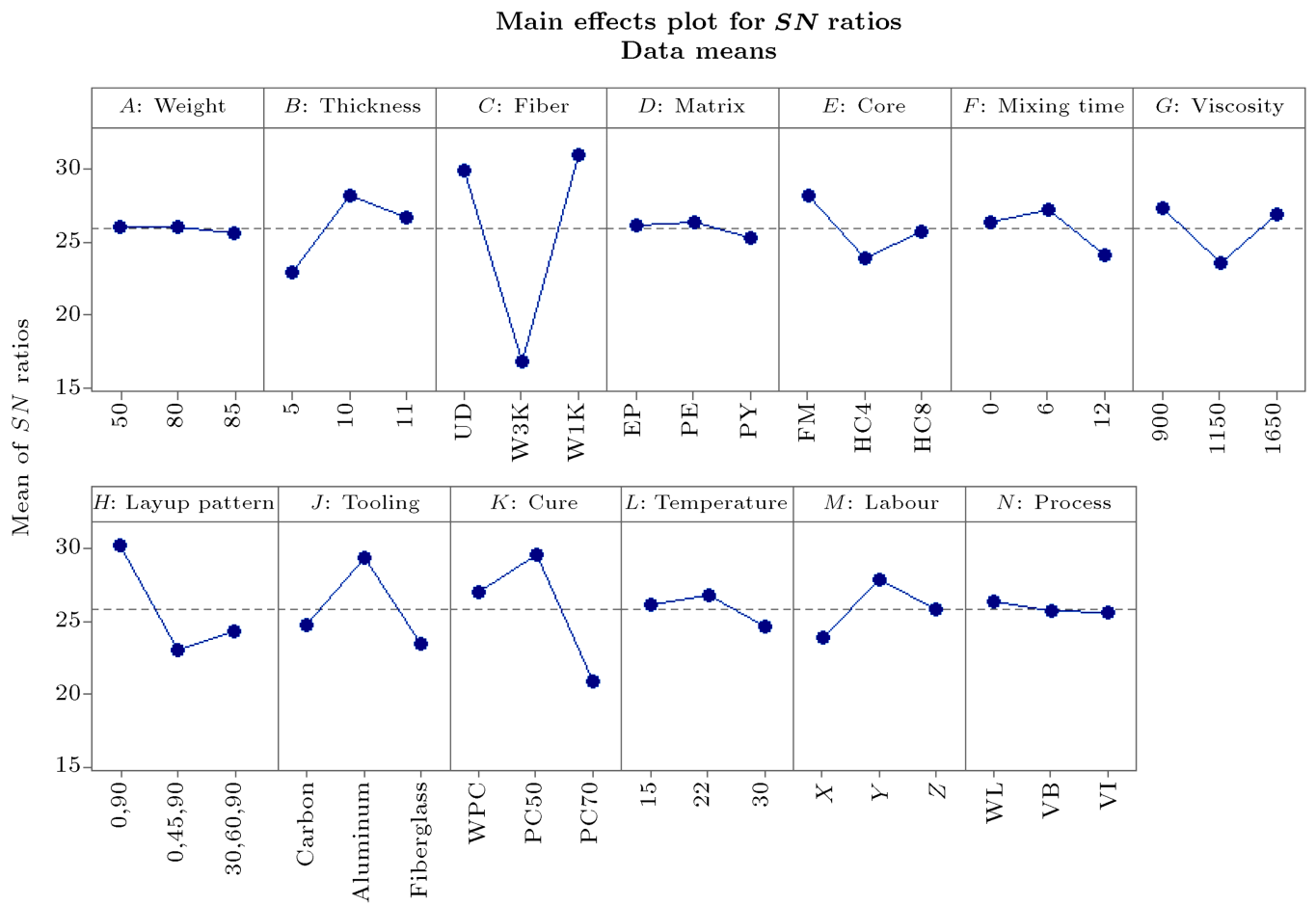

Signal-to-noise: Larger is better

Figure 8. $S / N_{\sigma}$ ratio graph for flexure stress. 


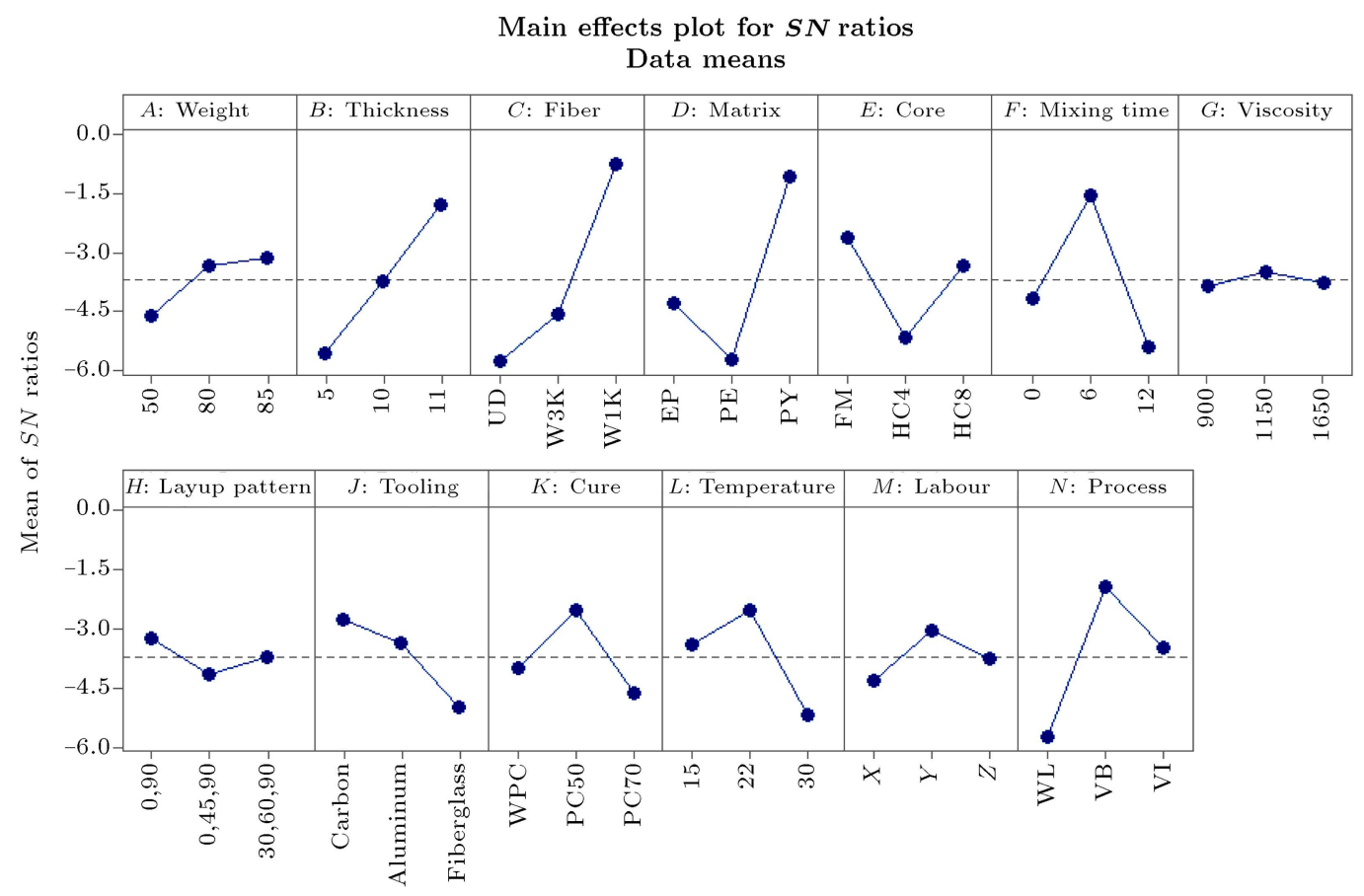

Signal-to-noise: Smaller is better

Figure 9. $S / N_{\varepsilon}$ ratio graph for flexure strain.

the most significant variables affecting flexure stress, while weight of laminate, type of process technique used, type of matrix, and temperature variation are relatively insignificant. Optimal control parameters for flexure stress were achieved at level 2 of weight ( $80 \mathrm{~g})$, level 2 of thickness $(10 \mathrm{~mm})$, level 3 of fiber pattern (W1K), level 2 of matrix (PE), level 1 of core (foam), level 2 of resin hardening mixing time (6 min), level 1 of viscosity (V1), level 2 of layup pattern $\left(0^{\circ}, 90^{\circ}\right)$, level 2 of tooling (aluminium), level 2 of cure (PC 50), level 2 of temperature $\left(22^{\circ} \mathrm{C}\right)$, level 2 of labour (Y), and level 1 of process (wet layup). Therefore, optimum level combination of control parameters determined for flexures stress is A2B2C3D2E1F2G1H1J2K2L2M2N1.

It is inferred from Table 5 and Figure 9 that fiber pattern, matrix type, resin hardening mixing time, and process techniques have significant effect on flexure strain, while viscosity, layup pattern, labour, and laminate weight have relatively insignificant effect. Optimal control parameters for flexure strain were achieved at level 3 of weight $(85 \mathrm{~g})$, level 3 of thickness (11 mm), level 3 of fiber pattern (W1K), level 3 of matrix (PY), level 1 of core (FM), level 2 of resin hardening mixing time (6 min), level 2 of viscosity (1150 mPa.s), level 1 of layup pattern $\left(0^{\circ}, 90^{\circ}\right)$, level 1 of tooling (carbon), level 2 of cure (PC 50), level 2 of temperature $\left(22^{\circ} \mathrm{C}\right)$, level 2 of labour (Y) and level 2 of process (vacuum bagging). Therefore, optimum level combination of control parameters determined for flexures strain is A3B3C3D3E1F2G2H1J1K2L2M2N2.
Results of experiments showed that fiber pattern is the most significant parameter for both flexure stress and strain. Cure agent and layup pattern are significant for flexure stress, but relatively insignificant in the case of strain. Variation in viscosity is significant in flexure stress, but highly insignificant in strain. Variation in laminate thickness and labour type is significant and has almost the same effect on both stress and strain. Variation in resin hardening mixing time is more pronounced in strain. Change of weight has not contributed much in flexural properties, whereas variation in temperature, matrix, and core material has more influence on strain compared to stress. Process technique used was insignificant in stress, but highly significant in the case of strain. It is an important finding that the optimal levels of 7 variables, including fiber pattern, core type, mixing time, layup pattern, cure, temperature, and labour, are the same for both flexure stress and strain.

\subsection{Validation of results}

Results obtained are confirmed through validation experiment. The optimal levels of each parameter obtained though experiments were selected, and confirmatory run was performed. The results of validation experiment confirmed the authenticity of optimal parameters, as shown in Table 6. Maximum value of flexure stress $(97.134 \mathrm{~N} / \mathrm{mm})$ and minimum value of flexure strain $(0.435 \%)$ were achieved, implying that the selected control parameters are the best to produce 
Table 6. Results of validation experiment.

\begin{tabular}{lcccc}
\hline Response variable & Optimal parameter levels & $\boldsymbol{S} / \boldsymbol{N}$ & Mean & $\boldsymbol{S D}$ \\
\hline Flexure Stress & A2B2C3D2E1F2G1H1J2K2L2M2N1 & 49.674 & $97.134\left(\mathrm{~N} / \mathrm{mm}^{2}\right)$ & 9.132 \\
Flexure Strain & A3B3C3D3E1F2G2H1J1K2L2M2N2 & 4.585 & $0.435 \%$ & 0.213 \\
\hline
\end{tabular}

polymer composite sandwich laminate structures with high stress and low strain values. The optimized levels of various parameters are useful for application in aviation, mechanical, sand civil industries where flexure properties are frequently encountered during operations.

\section{Conclusion}

This paper presents a novel quality framework for polymer composite manufacturing industries. It is concluded from the results that fiber pattern, post cure, tooling type, and layup pattern are the most significant parameters affecting flexure stress, whereas fiber pattern, matrix type, resin and hardener mixing time, and process techniques are the most significant parameters affecting flexure strain. Optimized values of flexure stress and flexure strain are obtained. Findings of this study are useful for polymer composite application in aviation, mechanical, sports, and civil industries. The optimized levels could be used in each industry depending upon the flexural requirements or life cycle use of products. Finally, the following areas of future research are proposed;

- To test and evaluate the proposed framework by selecting various combinations of control factors with more numbers of level;

- To test other quality characteristics of polymer composite, such as compressive strength, tensile strength, void, etc., and study the significance of control parameters on these attributes;

- To analyse interaction effect of significant control parameters on response variables through ANOVA study, and accordingly, mathematical models could be developed;

- Other process variables, design attributes, and material parameters may be added to the framework, and their significance of quality attributes arises to be evaluated.

\section{Acknowledgement}

The authors acknowledge National University of Science and Technology (NUST), Islamabad, School of Mechanical and Manufacturing Engineering (SMME), and School of Chemical and Material Engineering for their valuable discussions, data, support, and assistance in testing.

\section{References}

1. Federal Aviation Administration (FAA). "Quality control for the manufacture of vomposite structures", $A d$ visory Circular 21-26A, Washington, D.C. (2010). Retrieved from http://www.faa.gov/documentLibrary/ media/Advisory_Circular AC_21-26A.pdf.

2. Buczek, M.B., Backman, D. and Darfler, S. "The effect of variation in prepreg attributes on cured ply thickness", 45th Int. SAMPE Symp., Long Beach, California, pp. 136-147 (2000).

3. Federal Aviation Administration (FAA) "Composite aircraft structure", Advisory Circular AC 20107B, Washington, D.C. (2009). Retrieved from http://www.faa.gov/documentLibrary/media/ AC 20107B.pdf.

4. John, S.T. and Yeow, Ng. "Production control effect on composite material quality and stability", Report Joint Advanced Materials and Structures Center of Excellence, Submitted to Wichita State University (2008). https://depts.washington. edu/amtas/events/jams_06/Ng.pdf

5. Galappaththil, U.I.K. De Silva, A.M., Milos, D. and Macdonald, M. "Strategic quality control measures to reduce defects in composite wind turbine blades", Int. Conf. on Renew Energies and Power Quality, Bilbao, Spain (2013).

6. Potters, K.D. "Understanding the origins of defects and variability in composite manufacture", 17th Int. Conf. on Composite Materials, Edinburgh International Convention Centre, Edinburgh, UK (2009)

7. Mazumdar, S.K., Composite Manufacturing Materials, Products and Process Engineering, 1st Edn., pp. 118128, CRC Press, Boca Rotan, FL, USA (2001).

8. Flake, C.J., Manufacturing Processes for Advanced Composites, 1st Edn., pp. 17-25, Elsevier Science Ltd, Tacoma, WA, USA (2004).

9. DoD (Department of Defense) "Polymer matrix composites material usage, design, and analysis", Composite Materials Handbook, MIL-HDBK-17-3F, 3 (2002).

10. NASA "Design and manufacturing guideline for aerospace composites", Guideline No. GD-ED-2205 (2005).

11. Harris, C.E., Starnes, J.H. and Shuart, M.J. "Advanced durability and damage tolerance design and analysis methods for composite structures", Report 
NASA/TM-2003-212420, National Aeronautics and Space Administration, Hampton, VA 23681 (2003).

12. Harris, C.E., Starnes, J.H. and Shuart, M.J. "An assessment of the state-of-the-art in the design and manufacturing of large composite structures for aerospace vehicles", Report NASA/TM-2001-210844, National Aeronautics and Space Administration, Hampton, VA 23681 (2001).

13. Ranjit, K.R., A primer on Taguchi method, Society of Manufacturing Engineers, 2nd Edn., Van Nostrad Reinhold, New York (1990).

14. Paulo, J. "Design optimization of cutting parameters for turning metal matrix composites based on the orthogonal arrays", Journal of Material Process Technology, 132(1-3), pp. 340-344 (2003).

15. Basavarajapp, S., Chandramohan, G. and Paulo, J. "Application of Taguchi techniques to study dry sliding wear behavior of metal matrix composites", J. Mat. \& Design, 28(4), pp. 1393-1398 (2007).

16. Taguchi, G. and Konishi, S., Taguchi Methods Orthogonal Arrays and Linear Graphs: Tools for Quality Engineering, Dearborn, Amer Supplier Inst., pp. 35-38 (1987).

17. Taguchi, G., Taguchi on Robust Technology Development Methods, pp. 1-40, ASME Press, New York (1993).

18. ASTM Standard Test Methods for Flexural Properties of Unreinforced and Reinforced Plastics and Electrical Insulating Materials (April 1, 2010), DOI: 10.1520/D0790-10.

19. Byrne, D.M. and Taguchi, S. "The Taguchi approach to parameter designs", Quality Congress Transactions, American Society of Quality Control (177), pp. 168-177 (1986).

\section{Biographies}

Muhammad Asim is a talented, self-motivated, enthusiastic Aerospace Engineer with over 17 years of experience as Maintenance, Research, and Project Manager. He did his MS in Engineering Management. Presently, he is $\mathrm{PhD}$ scholar in the same field. The responsibilities held include project management, system integration, design/development, and maintenance management of aviation grade military systems. He has three years of teaching experience at
NUST (SEECS, NBS, and SCME), Islamabad. He has published 20 research papers in various international conferences.

Muhammad Zubair Khan (Sitara-e-Imtiaz) has a distinguished academic and professional career. He received his BSc degree in Mechanical Engineering in Pakistan; similarly, received his MPhil and $\mathrm{PhD}$ degrees from London, England. He has 36 years of diversified practical experience of $R \& D$. Also, he worked different engineering projects. He has held eminent positions at prestigious organizations of Pakistan (KRL \& AWC). Since 2003, he has been teaching as a visiting faculty scholar at UET Taxila and Wah Engineering College, University of Wah. He is an HEC approved supervisor for PhD in the field of Mechanical Engineering. Presently, he has been employed as a Professor by Institute of Space Technology. He published 35 papers in International and National Journals. He was awarded Sitari Imtiaz by the Government of Pakistan in recognition of outstanding contributions in the field of Mechanical Engineering.

Laraib Alam Khan received his $\mathrm{PhD}$ degree in Materials Sciences from Northwest Composites Centre (NWCC), School of Materials, University of Manchester, UK. He received his MS degree (Mechanical) from EME college NUST, and his BE in Mechanical Engineering from NED University, Karachi, Pakistan. He has been involved in manufacturing and various R\&D projects related to composite materials. He has experience and expertise of composite manufacturing processes and several mechanical tests for composite materials. He is the author of various research papers published in International Journals and Conferences.

Muhammad Umer obtained his MS degree in Engineering Management from CASE in 2006 and MS degree in Operation Research from London School of Economics. He has also obtained PhD degree in Manufacturing from School of Mechanical and Manufacturing NUST Islamabad. Since 2009, he has been contributing to Pakistani Academia and Industry in various areas and has ten years of National and International experience in manufacturing and supply chain with multinational companies. 